\title{
1 Multiple selection signatures in farmed Atlantic salmon adapted to different environments across Hemispheres
}

$4 \quad$ Running title: Selection signatures in farmed Atlantic salmon

${ }^{\text {a }}$ Facultad de Ciencias Veterinarias y Pecuarias, Universidad de Chile, Santiago, Chile.

${ }^{\mathrm{b}}$ Department of Animal Breeding and Genetics, Swedish University of Agricultural 11 Sciences, Uppsala, Sweden.

${ }^{\mathrm{c}}$ Department of Integrative Biology, University of California, Berkeley, CA, USA.

${ }^{\mathrm{d}}$ Marine Harvest, Kindrum, Fanad, C. Donegal, Ireland.

${ }^{\mathrm{e}}$ Benchmark Genetics Chile, Puerto Montt, Chile.

${ }^{\mathrm{f}}$ Facultad de Ciencias Agronómicas, Universidad de Chile, Santiago, Chile.

g Núcleo Milenio INVASAL, Concepción, Chile. 


\section{ABSTRACT}

29 Domestication of Atlantic salmon started approximately forty years ago, using both

30 artificial and natural selection strategies. Such selection methods are likely to have imposed

31 distinctive selection signatures on the salmon genome. Therefore, identifying differences in

32 selection signatures may give insights into the mechanism of selection and candidate genes

33 of biological and productive interest. Here, we used two complementary haplotype-based

34 statistics, the within-population integrated Haplotype Score test $(|\mathrm{iHS}|)$ and the cross-

35 population Extended Haplotype Homozygosity test (XP-EHH) to compare selection

36 signatures in four populations of Atlantic salmon with a common genetic origin. Using

37 |iHS| we found 24, 14, 16 and 26 genomic regions under selection in Pop-A, Pop-B, Pop-C,

38 and Pop-D, respectively. While using the XP-EHH test we identified 27, 25 and 15

39 potential selection regions in Pop-A/Pop-B, Pop-A/Pop-C and Pop-A/Pop-D, respectively.

40 These genomic regions harbor important genes such igflr and sh3rfl which have been

41 associated with growth related traits in other species. Our results contribute to the detection

42 of candidate genes of interest and help to understand the evolutionary and biological

43 mechanisms for controlling complex traits under selection in Atlantic salmon.

\section{$47 \quad$ Keywords}

48 Selection signatures, Salmo salar, domestication, SNP data, artificial selection. 


\section{BACKGROUND}

58 Atlantic salmon (Salmo salar L) were first farmed in Norway during the 1960s, and have

59 now become one of the most important aquaculture species (FAO 2016). Despite a 60 generation interval of three to four years, breeding programs have achieved rapid 61 improvement of economically important traits such as growth, sexual maturation and 62 disease resistance (GJEDREM et al. 2012). One of the first farmed populations named Mowi 63 strain, was established with fish from west coast rivers in Norway, with major contributions 64 from River Bolstad in the Vosso watercourse, River Årøy and possibly from the 65 Maurangerfjord area (VERSPOOR et al. 2007). Salmon from the Vosso and Årøy rivers are 66 characterized by large size and late maturity (VERSPOOR et al. 2007). Phenotypic selection 67 for growth, late maturation and fillet quality was the focus in this population until 1999 68 (Glover et al. 2009). Ova from this population were imported into Fanad Peninsula, 69 Ireland between 1982 and 1986 to establish an Irish-farmed population (NORRIS 1999). 70 Similarly, ova from this Irish farmed population were introduced to Chile in the early 71 1990s. These stocks were subsequently adapted to the biotic and abiotic factors present in 72 southern hemisphere conditions. Artificial selection and adaptation to captive environments 73 has left detectable genomic patterns in farmed Atlantic salmon populations, as evidenced 74 by differences between wild and farmed populations for several traits, such as growth rate 75 (ThODESEN et al. 1999; GlOvER et al. 2009; SOLBERG et al. 2012), predator awareness 76 (EINUM AND FLEMING 1997) and gene transcription patterns (ROBERGE et al. 2006; BICSKEI 77 et al. 2014; CHRISTIE et al. 2016).

79 Domestication processes are likely to have exerted selection pressures on certain genomic 80 regions that underlie traits of human interest or other traits involved in adaptation to captive 81 environments. Accordingly, positive selection pressures will cause the frequency of alleles 82 underlying favorable traits to increase rapidly in these domesticated populations. Linkage 83 disequilibrium between favorable mutations and neighboring loci will increase and spread, 84 given there is little opportunity for recombination over the brief time since the onset of 85 intense selection (SABETI et al. 2002). Analyses of these selection signatures in domestic 86 animals can provide further insights into the genetic basis of adaptation to diverse 87 environments and genotype/phenotype relationships (OLEKSYK et al. 2010; ANDERSSON 
88 2012). Access to genomic data through next-generation sequencing and high-throughput

89 genotyping technologies have made the comparison of genomic patterns of SNP variation

90 between different livestock breeds possible, allowing for the identification of putative

91 genomic regions and genes under selection in various species including cattle (FLORI et al.

92 2009), horses (PETERSEN et al. 2013; FRISCHKNECHT et al. 2016), sheep (KIJAS et al. 2012;

93 FARIELlO et al. 2014), pigs (AMARAL et al. 2011), Atlantic salmon (VASEMÄGI et al. 2005;

94 VASEMÄGI et al. 2012; MÄKINEN et al. 2014; GUTIERREZ et al. 2015; LóPEZ et al. 2018)

95 and tilapia (Hong XiA et al. 2015).

97 There are several approaches for detecting selection signatures in the genome, one of which

98 relies on the length or variability of haplotypes. Directional selection acting on a new

99 beneficial mutation results in the haplotype harboring the mutation to increase in frequency

100 and to be longer than average. In order to exploit this, Sabeti et al (2002), proposed the

101 extended haplotype homozygosity $(\mathrm{EHH})$ statistic to detect of positive selection in a

102 population, which is specifically the probability that two randomly selected haplotypes are

103 identical-by-descent over their entire length around a core SNP (Sabeti et al 2002). This

104 concept forms the basis for other haplotype homozygosity based metrics, such as the

105 relative EHH (REHH) (SABETI et al. 2002) and the widely-used integrated Haplotype Score

106 (|iHS|) (VoIGHT et al. 2006). |iHS| compares EHH between derived and ancestral alleles

107 within a population and has the most power to detect selection when the selected allele is at

108 intermediate frequencies in the population (SABETI et al. 2006; VOIGHT et al. 2006). To

109 detect selection signatures between populations, the cross-population Extended Haplotype

110 Homozygosity test (XP-EHH) compares the integrated EHH profiles between two

111 populations at the same SNP. It was designed to detect ongoing or nearly fixed sites

112 harboring selection in one population (SABETI et al. 2007).

113 Although previous studies have already been carried out to detect selection signatures in

114 Atlantic salmon (MÄKINEN et al. 2014; GUTIERREZ et al. 2015; LIU et al. 2016; LÓPEZ et al.

115 2018) exploration of selection signatures in additional populations will illuminate how

116 genetic variation among the different strains, adapted to different culture conditions, across

117 hemispheres has not been assessed yet. Herein we used an Affymetrix 200K SNP array

118 dataset to investigate selection signatures in farmed Atlantic salmon populations from the 
119 same origin, cultivated in Ireland and Chile. We identified several selection signatures

120 using two haplotype-based approaches (|iHS| and XPEHH) at the whole genome level in

121 four Atlantic salmon populations. These findings are important as they highlight regions of

122 the genome that might benefit economically relevant attributes, such as growth, resistance

123 to local diseases and adaptation to specific environmental conditions.

\section{4}

\section{MATERIALS AND METHODS}

\section{Samples, genotyping and quality control.}

128 We used a total of 270 individuals from four farmed Atlantic salmon populations of

129 Norwegian origin (Pop-A, $\mathrm{n}=40$; Pop-B, $\mathrm{n}=71$; Pop-C, $\mathrm{n}=85$; Pop-D, $\mathrm{n}=74$ ). Pop-A

130 fish are from the Irish strain (Fanad) originating from the west coast Rivers of Norway, as

131 described in the Introduction section. Artificial selection for improving growth, maturity

132 and fillet quality was applied from the beginning in this population (GLOVER et al. 2009).

133 We estimated that this population had been under artificial selection for at least ten

134 generations. Pop-B and Pop-C are two different Chilean populations, established with fish

135 from two different year classes of the same Irish strain (Fanad) in the 1990s. Pop-B and

136 Pop-C have been farmed and adapted to the Los Lagos Region, Chile $\left(42^{\circ} \mathrm{S} 72^{\circ} \mathrm{O}\right)$. Pop-D

137 is another Chilean population founded with fish from the same Irish farmed strain but 138 adapted to the $\mathrm{XII}^{\text {nd }}$ Region, Magallanes, Chile $\left(53^{\circ} \mathrm{S} 70^{\circ} \mathrm{O}\right)$. Pop-B, Pop-C and Pop-D

139 populations experienced four generations of selective breeding for growth in Chilean

140 farming conditions at the time of sampling.

142 Genotyping of all populations was performed using Affymetrix's Atlantic salmon 200K 143 SNP Chip described in YÁÑEZ et al. (2016). We assessed SNP quality control using Axiom

144 Genotyping Console (GTC, Affymetrix) and SNPolisher (an R package developed by 145 Affymetrix) i) removing SNPs that did not match with high quality clustering patterns, 146 according to the best practices recommended by Affymetrix, ii) removing SNPs with call 147 rate lower than $95 \%$ and iii) we discarded individuals with genotyping call rate under $90 \%$.

148 We used only SNPs that mapped to chromosomes in the newest version of the Atlantic 
149 salmon reference genome, ICSAG_v2 (GenBank: GCA_000233375.4). After quality

150 control filtering, 146,102 SNPs remained for downstream analyses.

152 Genetic diversity and population structure

154 We evaluated genetic diversity in terms of the observed heterozygosity $\left(\mathrm{H}_{\mathrm{O}}\right)$ and expected 155 heterozygosity $\left(\mathrm{H}_{\mathrm{E}}\right)$ calculated with PLINK v1.07 (PuRCELL et al. 2007). To investigate 156 population structure based on individual ancestry proportions, we performed model-based 157 clustering assuming no prior knowledge about strain origins in ADMIXTURE 1.2.2 158 (ALEXANDER et al. 2009). We performed 10 separate randomly seeded runs for each 159 number $\mathrm{K}$ of ancestral populations $(1<\mathrm{K}<20)$ and selected the optimum $\mathrm{K}$ according to the 160 lowest value of the cross-validation error. The aforementioned analyses were conducted 161 using a total of 20,000 SNPs after retaining only those with linkage disequilibrium (LD) 162 values of at most 0.2 to minimize possible confounding effects of LD on the underlying 163 patterns of genetic structure.

\section{Selection signatures, gene annotation and functional analyses}

167 To detect potentially regions harboring selection signatures, two complementary haplotype-

168 based detection methods, iHS and XPEHH, were used for within and between population 169 analyses, respectively.

170 Detection of within-population selection signatures using $\boldsymbol{i H S}$. The iHS score is based

171 on the ratio of extended haplotype homozygosity (EHH) for haplotypes anchored with the 172 ancestral versus derived allele. The ancestral allele state for salmon is unknown and so to 173 avoid losing SNPs by trying to polarize them from publicly available outgroup references, 174 we assumed that the major allele represented the ancestral state as used by Bahbahani et al 175 (2015). We phased the haplotypes using Beagle (BROWNING AND BROWNING 2009). Single176 site iHS values were calculated across the genome for each population. $|\mathrm{iHS}|$ scores were 177 calculated using the REHH package (GAUTIER AND VITALIS 2012) and a score threshold of 1783.0 was used to infer candidate genomic regions under selection. 
181 statistic compares the integrated EHH between two populations at the same SNP, in order

182 to identify selection based on overrepresented haplotypes in one of the populations,

183 detecting entirely or approximately fixed sites (SABETI et al. 2007). The direction of

184 selection can be determined from the sign of XP-EHH scores, whereby negative XP-EHH

185 scores suggest selection in the 'reference' population, whereas positive scores suggest

186 selection in the 'observed' population. Pop-A was used as the reference population to the

187 other three populations, hence there were three pairs of comparisons.

\section{Gene functional annotation}

190 Genomic regions harboring SNPs showing evidence of selection were annotated based on 191 the ICSAG_v2 reference genome (LIEN et al. 2016) using SnpEff (CINGOLANI et al. 2012).

192 Gene transcripts from these candidate regions were aligned (using blastx) (ALTSCHUL et al. 193 1990) to the zebra fish (Danio rerio) peptide reference database (downloaded from 194 http://www.ensembl.org/) to determine gene identify. As evidence of homology we used an 195 e-value $\square 0$ and then retrieved the zebra fish gene identifiers and gene ontology (GO) 196 information from the ensembl biomart database (http://www.ensembl.org/biomart).

\section{RESULTS}

Genetic diversity and structure.

We investigated genetic diversity within each population using SNPs filtered for missing data per individual $(\max 10 \%)$, missing data per marker $(\max 5 \%)$ and allele frequency

203 (min 5\%) as described in the Materials and Methods section. A total of 146,103 SNPs were

204 retained for analyses after these quality control steps. Observed heterozygosity levels were

205 similar across the four domestic populations. And was slightly higher than expected for

206 populations A, B and C, and even higher in population D (See Table 1).

207 Admixture analysis was used to determine the composition of ancestral lineages among 208 individuals to offer insight into the observed genetic variation. We found $\mathrm{K}=12$ ancestral

209 lineages to be optimal in describing the ancestry of the individuals across the 4 populations 210 (Figure 1). 


\section{Candidate regions under selection - $|\mathbf{i H S}|$}

213 We used the haplotype-based |iHS| test to look for selection within populations. For each 214 population we defined candidate selection regions using the thresholds of $|\mathrm{iHS}|>3$ (Figure

2152 and Table 2). Candidate regions were retained if two SNPs separated by $\leq 500 \mathrm{~Kb}$ passed 216 this threshold and were annotated using the positions of the first and last SNP as 217 boundaries, extending $500 \mathrm{~Kb}$ to each side. In Pop-A we identified 120 markers putatively 218 under selection among ten chromosomes, Ssa02 and Ssa10 combined had approximately 60 219 SNPs. The highest score $(-\log (\mathrm{p}$-value $)=5.04)$ was found in Ssa05 in a region of 6,7 Kb, 220 associated with the CR762469.1 gene; other high scores were found in Ssa10 and Ssa01, 221 nearby to mipoll, furinb, $\operatorname{csnk} 1 g 2 a$ and $r s 17$. Other candidate genes undergoing selection 222 for this population are shown in Supplementary Table S1.

224 In Pop-B fourteen regions passed the threshold, distributed among eight chromosomes 225 (Ssa1, 6, 10, 12, 13, 14, 16, and 27). The highest score was in Ssa06, harboring the SASH1 226 gene. Ssa01 and Ssa13 encompassed 4 and 3 regions under selection, respectively, 227 spanning from $11 \mathrm{~Kb}$ to $228 \mathrm{~Kb}$. A total of 24 genes were located in these regions 228 (Supplementary Table S1).

In Pop-C |iHS| detected 121 SNPs passing the threshold and we annotated sixteen genomic

231 regions. Ssa22 showed the highest scores and larger regions under selection, harboring 232 genes such kcnkf, sc61a, mapk3, f264 and cdh2. Ssa16 and Ssa19 also exhibited high |iHS| 233 scores spanning regions $3 \mathrm{~Kb}$ to $1788 \mathrm{~Kb}$.

235 Finally, Pop-D presented the highest number of SNPs (134 SNPs) above the threshold 236 compared with other populations, distributed across 11 chromosomes. We defined 25 237 genomic regions under selection, most of them located in Ssa26, where the highest |iHS| 238 scores were also found. Genes such as uqcrfs1, neto1, itfg1 and phkb were found in these 239 regions. Ssa24 also presented higher $|\mathrm{iHS}|$ values in one of its regions associated with tchp, 240 ube3b and myo1ha among others. Details of genes and regions can be found in 241 Supplementary Table S1. 


\section{Candidate regions under selection - XPEHH}

244 We also looked for selection signatures using the XPEHH test between the following 245 populations pairs: A/B; A/C and A/D (Figure 3). We detected, 437 (A/B), 764 (A/C) and

246262 (A/D) XPEHH scores outlier SNPs indicative of selection (Table 3). We considered

247 potential genomic regions under selection as those containing two or more consecutive 248 SNPs less than $500 \mathrm{~Kb}$ apart and that had XPEHH score > 3. After merging overlapping 249 regions 27,25 and 15 candidate regions were identified for $\mathrm{A} / \mathrm{B}, \mathrm{A} / \mathrm{C}$ and $\mathrm{A} / \mathrm{D}$ comparisons 250 respectively. The total length of the candidate regions was $10.13 \mathrm{Mb}$ for $\mathrm{A} / \mathrm{B}, 12.11 \mathrm{Mb}$ for $251 \mathrm{~A} / \mathrm{C}$ and $4.05 \mathrm{Mb}$ for $\mathrm{A} / \mathrm{D}$. Comparison between $\mathrm{A} / \mathrm{C}$ yielded negative results in 252 chromosome Ssa14 and Ssa16, furthermore comparison A/D yielded negative results in 253 Ssa14, Ssa24 and Ssa26, suggesting selection in the reference population (A). The gene 254 annotation revealed in $\mathrm{A} / \mathrm{B}$ the plecb gene on Ssa02 and myolcb, slc43a2a and ywhae1 255 genes on Ssa09, associated with the highest values of XPEHH. In A/C the chromosome 256 Ssa10 presented a large number of SNPs and regions putatively under selection. Also this 257 chromosome presented the highest scores; genes such as fnbpll, bcar3, slc5a9 and fryl were 258 associated with these values. The highest values for A/D were also located on Ssa10 with $259 \operatorname{lh} x 4$, shr3rfl and ftr33 genes. The negative values of XPEHH harboring genes such agla, $260 k c m f 1, c d s 1$ and $t s h z 3 b$ suggest selection on population A.

262 Gene ontology for candidate genes under selection.

263 To further explore the functions of the candidate genes nearby markers showing evidence 264 of selection signatures, we annotated the candidate genes detected by both methods using 265 DAVID browser (https://david-d.ncifcrf.gov). These candidate genes were enriched in 14 266 gene ontology terms. None of these categories were common across all four populations, 267 but Developmental process and Multicellular organismal process were common on Pop B268 C and D. Regulation of biological process was shared for Pop A -B and D; Single269 organism process was common for Pop A -B and C; Biological regulation was found in 270 Pop-B and Pop-D; and Growth and Locomotion were common for Pop-B and Pop-C. 271 Anatomical structure development, Biosynthetic process, Cell growth and Single272 multicellular organism process were present only in Pop-A; while Localization and 273 Signaling were found only in Pop-B (4). 


\section{DISCUSSION}

275 In this study two complementary tests were used to detect genome wide selection

276 signatures within and between four Atlantic salmon populations with Norwegian origin.

277 We used $|\mathrm{iHS}|$ test to evaluate selection signatures within populations and XPEHH to

278 evaluate across populations. We used the oldest population as the reference population

279 when using XPEHH to evaluate the effect of domestication and artificial selection in three

280 different locations in Chile.

\section{Structure and diversity}

282 To examine genetic population structure and relationships among the major groups of 283 salmon, we conducted an ADMIXTURE analyses based on high-quality SNP data. This 284 analysis revealed twelve clusters, which was expected considering the admixed origin of 285 these populations (VERSPOOR et al. 2007). The four populations used in this study come 286 from the Mowi strain, which was created, using samples from several rivers along the west 287 coast of Norway (NORRIS et al. 1999). The population with the lowest level of admixture 288 was Pop-A, which was also the population with the lowest genetic diversity, a condition 289 that could reflect a higher intensity of artificial selection in this population. Intense artificial 290 selection causes loss of genetic variation as a consequence of the mating of related 291 individuals (GJEDREM 2005). Pop-B and Pop-C showed very similar patterns of

292 heterozygosity and admixture level, which was expected due to the similar breeding 293 practices and environmental conditions to which they have been subjected. Pop-D, 294 however, showed the highest level of heterozygosity and a more complex pattern of 295 admixture, likely produced by a lower pressure of artificial selection on this population. 296 Recent genetic introgression cannot be discarded for Pop-D given the potential of crosses 297 with a different strain for management issues. The results presented here also reinforce the 298 notion that a few generations (at least four in this particular case) are sufficient to generate 299 large changes in terms of genetic structure in farmed Atlantic salmon populations, with the 300 same genetic origin, which have been subjected to different management and 301 environmental conditions. Estimates of inbreeding coefficient $\left(\mathrm{F}_{\text {IS }}\right)$ showed the lowest 302 value in Pop-D, which is consistent with the heterozygosity level in this population. Pop-A 303 presented the second lowest value, despite the fact that this population has been subjected 
304 to the most intense selection pressure probably due to a better inbreeding management with

305 the use of DNA fingerprinting technology to know relatedness among individuals in order 306 to avoid inbreeding.

\section{Selection signatures}

309 As expected the highest |iHS| scores were found in Pop-A because this population has been 310 subjected to more intense artificial selection pressures for a longer time. The number of 311 SNPs under selection detected by this method was similar in Pop-A, Pop-C and Pop-D, but

312 lower in Pop-B. We suggest that this difference is due to the fact that the $|\mathrm{iHS}|$ test has little 313 power to detect signals near fixation (SABETI et al. 2007; SIMIANER et al. 2010). XPEHH, 314 which is more powerful at detecting selection signatures at or near fixation (Sabeti 2007), 315 detected a similar number of regions putatively under selection in Pop-B and Pop-C, but 316 lower in Pop-D. Conversely, |iHS| detected more SNP in this population, suggesting loci 317 under selection in Pop-D have experienced weaker pressure of artificial selection and a 318 greater impact of natural selection, which has prevented allele fixation. Overlaps among 319 regions detected by $|\mathrm{iHS}|$ method, were found only when using pairs of populations, that is, 320 a common region was found between Pop-A/B, Pop-A/C, Pop-A/D, Pop-B/C, Pop-B/D and 321 Pop-C/D. No overlap was found among four populations or when using any combination of 322 three. XPEHH detected a higher number of shared regions among populations, specifically 323 in Ssa02, which was common to all 3 tested populations. In addition, shared regions were 324 found in population pairs B/C and Pop-D/C. A greater number of shared regions detected 325 by XPEHH could be explained by a greater power to detect regions that have experienced 326 older selection events (SABETI et al. 2007; KLIMENTIDIS et al. 2011) than those detectable 327 by $|\mathrm{iHS}|$. Therefore, these regions may be explaining selection signatures that originated 328 before these populations were brought to Chile.

\section{Domestication traits in salmon}

330 Selection signatures found in this study may be involved in some desirable economic traits 331 in salmon production as well as traits that are typically under the effect of domestication.

332 All populations used in this study have been subjected to artificial selection to improve 333 growth rate. According to the functional annotations of the candidate genes, several 
334 biological processes were found to be involved with growth and development, such as the

335 Development process and Regulation of Biological/metabolic processes. Additionally,

336 some of the genes identified have been associated with growth traits in other species; such

337 sh3rfl in chicken and cattle (HANOTTE et al. 2003; RUBIN et al. 2010) or igflr, which was

338 previously found to be a size locus of large effect in dogs (SUTTER et al. 2007; HOOPES et

339 al. 2012). We suggest that these genes may be under selection for improving growth related

340 traits in salmon. On the other hand, we also identified genes such scaper, clstn3 and pex5

341 related to mental disorders in humans (GLATT et al. 2005; PETTEM et al. 2013). Other genes

342 related to behavioral traits have be found in other Atlantic salmon strains, as well (Lopez et

343 al, 2018), suggesting that artificial selection acts on behavioral traits in salmon as in other

344 domestic animals (Clutton-Brock 1999).

\section{CONCLUSIONS}

347 In the present study, several candidate genomic regions with selection signatures were

348 identified using two haplotype based methods, $|\mathrm{iHS}|$ and XPEHH in four populations of

349 Atlantic salmon. These genomic regions harbored important genes that enriched $\mathrm{G}$ terms

350 including growth, developmental processes, and have been associated with growth and

351 behavior in other species. These finding improve our understanding of genomic variants

352 undergoing selection in domestic populations of Atlantic salmon.

\section{Ethics approval and consent to participate}

355 The sampling protocol was previously approved by The Comité de Bioética Animal,

356 Facultad de Ciencias Veterinarias y Pecuarias, Universidad de Chile (Certificate $N^{\circ} 29-$ 357 2014).

\section{Consent for publication}

360 Not applicable 


\section{Availability of data and material}

363 Genotype data for each population is available from the online digital repository figshare

364 https://figshare.com/s/83efa70722ed5ada023a

\section{Competing Interest}

367 The authors have no conflicts of interest to declare

370 This work has been conceived on the frame of the grant CORFO (11IEI-12843 and 371 12PIE17669), Government of Chile.

\section{Author's contributions}

373 MEL and JMY conceived the research idea. MEL drafted the manuscript and carried out

374 the analyses. TL supervised the data analyses and contributed to discussion and writing.

375 TL, AN, JPL, RN, and JMY reviewed the manuscript. All authors read and approved the 376 final manuscript.

\section{Acknowledgements}

381 MEL acknowledges the National Commission of Scientific and Technologic Research 382 (CONICYT) for the funding through the National PhD funding program. JMY is supported 383 by Núcleo Milenio INVASAL funded by Chile's government program, Iniciativa Científica 384 Milenio from Ministerio de Economía, Fomento y Turismo 


\section{REFERENCES}

Alexander, D. H., J. Novembre and K. Lange, 2009 Fast model-based estimation of ancestry in unrelated individuals. Genome Research.

Altschul, S. F., W. Gish, W. Miller, E. W. Myers and D. J. Lipman, 1990 Basic local alignment search tool. J Mol Biol 215: 403-410.

Amaral, A. J., L. Ferretti, H.-J. Megens, R. P. M. A. Crooijmans, H. Nie et al., 2011 Genome-Wide Footprints of Pig Domestication and Selection Revealed through Massive Parallel Sequencing of Pooled DNA. PLoS ONE 6: e14782.

Andersson, L., 2012 How selective sweeps in domestic animals provide new insight into biological mechanisms. Journal of Internal Medicine 271:1-14.

Bahbahani, H., H. Clifford, D. Wragg, M. N. Mbole-Kariuki, C. Van Tassell et al., 2015 Signatures of positive selection in East African Shorthorn Zebu: A genome-wide single nucleotide polymorphism analysis. Scientific reports 5 .

Bicskei, B., J. E. Bron, K. A. Glover and J. B. Taggart, 2014 A comparison of gene transcription profiles of domesticated and wild Atlantic salmon (Salmo salar L.) at early life stages, reared under controlled conditions. BMC Genomics 15: 884.

Browning, B., and S. Browning, 2009 A unified approach to genotype imputation and haplotype-phase inference for large data sets of trios and unrelated individuals. Am J Hum Genet 84: 210 - 223.

Christie, M. R., M. L. Marine, S. E. Fox, R. A. French and M. S. Blouin, 2016 A single generation of domestication heritably alters the expression of hundreds of genes. Nature Communications 7: 10676.

Cingolani, P., A. Platts, L. Wang, M. Coon, T. Nguyen et al., 2012 A program for annotating and predicting the effects of single nucleotide polymorphisms, SnpEff: SNPs in the genome of Drosophila melanogaster strain w1118; iso-2; iso-3. Fly 6: 80-92.

Clutton-Brock, J., 1999 A natural history of domesticated mammals. Cambridge University Press.

Einum, S., and I. Fleming, 1997 Genetic divergence and interactions in the wild among native, farmed and hybrid Atlantic salmon. J Fish Biol 50.

FAO, 2016 The State of World Fisheries and Aquaculture 2016.

Contributing to food security and nutrition for all.: $200 \mathrm{pp}$.

Fariello, M.-I., B. Servin, G. Tosser-Klopp, R. Rupp, C. Moreno et al., 2014 Selection Signatures in Worldwide Sheep Populations. PLoS ONE 9: e103813.

Flori, L., S. Fritz, F. Jaffre zic, M. Boussaha, I. Gut et al., 2009 The genome response to artificial selection: a case study in dairy cattle. PLoS ONE 4: e6595.

Frischknecht, M., C. Flury, T. Leeb, S. Rieder and M. Neuditschko, 2016 Selection signatures in Shetland ponies. Animal genetics.

Gautier, M., and R. Vitalis, 2012 rehh: an R package to detect footprints of selection in genome-wide SNP data from haplotype structure. Bioinformatics 28: 1176-1177.

Gjedrem, T., 2005 Selection and Breeding Programs in Aquaculture. Springer, Dordrecht, The Netherlands.

Gjedrem, T., N. Robinson and M. Rye, 2012 The importance of selective breeding in aquaculture to meet future demands for animal protein: A review. Aquaculture 350353: 117-129. 
435

436

437

438

439

440

441

442

443

444

445

446

447

448

449

450

451

452

453

454

455

456

457

458

459

460

461

462

463

464

465

466

467

468

469

470

471

472

473

474

475

476

477

478

479

480

Glatt, S. J., I. P. Everall, W. S. Kremen, J. Corbeil, R. Sásik et al., 2005 Comparative gene expression analysis of blood and brain provides concurrent validation of SELENBP1 up-regulation in schizophrenia. Proceedings of the National Academy of Sciences of the United States of America 102: 15533-15538.

Glover, K., H. Ottera, R. Olsen, E. Slinde, G. Taranger et al., 2009 A comparison of farmed, wild and hybrid Atlantic salmon (Salmo salar L.) reared under farming conditions. Aquaculture 286.

Gutierrez, A. P., J. M. Yáñez and W. S. Davidson, 2015 Evidence of recent signatures of selection during domestication in an Atlantic salmon population. Marine Genomics.

Hanotte, O., Y. Ronin, M. Agaba, P. Nilsson, A. Gelhaus et al., 2003 Mapping of quantitative trait loci controlling trypanotolerance in a cross of tolerant West African N'Dama and susceptible East African Boran cattle. Proceedings of the National Academy of Sciences of the United States of America 100: 7443-7448.

Hong Xia, J., Z. Bai, Z. Meng, Y. Zhang, L. Wang et al., 2015 Signatures of selection in tilapia revealed by whole genome resequencing. Scientific Reports 5: 14168.

Hoopes, B. C., M. Rimbault, D. Liebers, E. A. Ostrander and N. B. Sutter, 2012 The insulin-like growth factor 1 receptor (IGF1R) contributes to reduced size in dogs. Mammalian genome : official journal of the International Mammalian Genome Society 23: 780-790.

Kijas, J. W., J. A. Lenstra, B. Hayes, S. Boitard, L. R. Porto Neto et al., 2012 GenomeWide Analysis of the World's Sheep Breeds Reveals High Levels of Historic Mixture and Strong Recent Selection. PLoS Biol 10: e1001258.

Klimentidis, Y. C., M. Abrams, J. Wang, J. R. Fernandez and D. B. Allison, 2011 Natural selection at genomic regions associated with obesity and type-2 diabetes: East Asians and sub-Saharan Africans exhibit high levels of differentiation at type-2 diabetes regions. Human genetics 129: 407-418.

Lien, S., B. F. Koop, S. R. Sandve, J. R. Miller, M. P. Kent et al., 2016 The Atlantic salmon genome provides insights into rediploidization. Nature 533: 200-205.

Liu, L., K. P. Ang, J. A. K. Elliott, M. P. Kent, S. Lien et al., 2016 A genome scan for selection signatures comparing farmed Atlantic salmon with two wild populations:

Testing colocalization among outlier markers, candidate genes, and quantitative trait loci for production traits. Evolutionary applications 10: 276-296.

López, M. E., L. Benestan, J. S. Moore, C. Perrier, J. Gilbey et al., 2018 Comparing genomic signatures of domestication in two Atlantic salmon (Salmo salar L) populations with different geographical origins. Evolutionary Applications 0.

Mäkinen, H., A. Vasemägi, P. McGinnity, T. F. Cross and C. R. Primmer, 2014 Population genomic analyses of early-phase Atlantic Salmon (Salmo salar) domestication/captive breeding. Evolutionary Applications 8: 93-107.

Norris, A., 1999 Microsatellite genetic variation between and within farmed and wild Atlantic salmon (Salmo salar) populations. Aquaculture 180.

Norris, A. T., D. G. Bradley and E. P. Cunningham, 1999 Microsatellite genetic variation between and within farmed and wild Atlantic salmon (Salmo salar) populations. Aquaculture 180.

Oleksyk, T. K., M. W. Smith and S. J. O'Brien, 2010 Genome-wide scans for footprints of natural selection. Philosophical Transactions of the Royal Society B: Biological Sciences 365: 185-205. 
481

482

483

484

485

486

487

488

489

490

491

492

493

494

495

496

497

498

499

500

501

502

503

504

505

506

507

508

509

510

511

512

513

514

515

516

517

518

519

520

521

522

523

524

525

526

527
Petersen, J. L., J. R. Mickelson, A. K. Rendahl, S. J. Valberg, L. S. Andersson et al., 2013 Genome-wide analysis reveals selection for important traits in domestic horse breeds. PLoS Genet 9.

Pettem, K. L., D. Yokomaku, L. Luo, M. W. Linhoff, T. Prasad et al., 2013 The specific $\alpha$ neurexin interactor calsyntenin-3 promotes excitatory and inhibitory synapse development. Neuron 80: 113-128.

Roberge, C., S. Einum, H. Guderley and L. Bernatchez, 2006 Rapid parallel evolutionary changes of gene transcription profiles in farmed Atlantic salmon. Molecular Ecology 15: 9-20.

Rubin, C.-J., M. C. Zody, J. Eriksson, J. R. S. Meadows, E. Sherwood et al., 2010 Wholegenome resequencing reveals loci under selection during chicken domestication. Nature 464: 587-591.

Sabeti, P., D. Reich, J. Higgins, H. Levine, D. Richter et al., 2002 Detecting recent positive selection in the human genome from haplotype structure. Nature 419: 832 - 837.

Sabeti, P., S. Schaffner, B. Fry, J. Lohmueller, P. Varilly et al., 2006 Positive natural selection in the human lineage. Science 3129: $1614-1620$.

Sabeti, P., P. Varilly, B. Fry, J. Lohmueller, E. Hostetter et al., 2007 Genome-wide detection and characterization of positive selection in human populations. Nature 449: 913 - 918.

Simianer, H., S. Qanbari and D. Gianola, 2010 Detection of selection signatures within and between cattle populations. Proceedings of 9th World Congress on Genetics Applied to Livestock Production.

Solberg, M. F., B. O. Kvamme, F. Nilsen and K. Glover, 2012 Effects of environmental stress on mRNA expression levels of seven genes related to oxidative stress and growth in Atlantic salmon Salmo salar L. of farmed, hybrid and wild origin. BMC Res Notes 5.

Sutter, N. B., C. D. Bustamante, K. Chase, M. M. Gray, K. Zhao et al., 2007 A single IGF1 allele is a major determinant of small size in dogs. Science (New York, N.Y.) 316: $112-115$.

Thodesen, J., B. Grisdale-Helland, S. J. Helland and B. Gjerde, 1999 Feed intake, growth and feed utilization of offspring from wild and selected Atlantic salmon (Salmo salar). Aquaculture 180: 237-246.

Vasemägi, A., J. Nilsson, P. McGinnity, T. Cross, P. O'Reilly et al., 2012 Screen for Footprints of Selection during Domestication/Captive Breeding of Atlantic Salmon. Comparative and Functional Genomics 2012: 1-14.

Vasemägi, A., J. Nilsson and C. R. Primmer, 2005 Expressed sequence tag-linked microsatellites as a source of gene-associated polymorphisms for detecting signatures of divergent selection in Atlantic salmon (Salmo salar L.). Mol Biol Evol 22: 1067-1076.

Verspoor, E., L. Stradmeyer and J. L. Nielsen, 2007 The Atlantic salmon: genetics, conservation and management. John Wiley \& Sons.

Voight, B., S. Kudaravalli, X. Wen and J. Pritchard, 2006 A map of recent positive selection in the human genome. PLoS Biology 4: e72.

Yáñez, J. M., S. Naswa, M. E. López, L. Bassini, K. Correa et al., 2016 Genomewide single nucleotide polymorphism discovery in Atlantic salmon (Salmo salar): validation in wild and farmed American and European populations. Molecular Ecology Resources: n/a-n/a. 
bioRxiv preprint doi: https://doi.org/10.1101/525550; this version posted January 20, 2019. The copyright holder for this preprint (which was not certified by peer review) is the author/funder. All rights reserved. No reuse allowed without permission.

528

529

530

531

532

533

534

535

536

537

538

539

540

541

542

543

544

545

546

547

548

549

550

551

552

553

554

555

556

557

558

559

560

561

562

563

564

565

566

567

568

569

570

571

572 
bioRxiv preprint doi: https://doi.org/10.1101/525550; this version posted January 20, 2019. The copyright holder for this preprint (which was not certified by peer review) is the author/funder. All rights reserved. No reuse allowed without permission.

Table 1. Mean genetic diversity (Observed heterozygosity and expected heterozygosity) of four Atlantic salmon populations

573

574

575

576

577

578

Population $\quad \mathrm{H}_{\mathrm{o}} \quad \mathrm{H}_{\mathrm{e}}$

579

580

581

582

583

584

585

586

587

588

589

590

591

592

593

594

595

596

597

598

599

600

601

602

603

604

605

606

607

608

609

610 
Table 2. Number of SNPs identified by $|\mathrm{iHS}|$ among populations and chromosomes.

\begin{tabular}{|c|c|c|c|c|}
\hline & Pop-A & Pop-B & Pop-C & Pop-D \\
\hline Ssa01 & 14 & 11 & 2 & 15 \\
\hline Ssa02 & 31 & & & \\
\hline Ssa03 & & & & 9 \\
\hline Ssa04 & & & & 1 \\
\hline Ssa05 & 2 & 1 & 5 & \\
\hline Ssa06 & 1 & 6 & & \\
\hline Ssa07 & 3 & & & \\
\hline \multicolumn{5}{|l|}{ Ssa08 } \\
\hline Ssa09 & 6 & & 2 & \\
\hline Ssa10 & 43 & 3 & 6 & 14 \\
\hline Ssa11 & & & 2 & \\
\hline Ssa12 & 3 & 7 & & 1 \\
\hline Ssa13 & 4 & 16 & 3 & 2 \\
\hline Ssa14 & 4 & 3 & 4 & 4 \\
\hline Ssa15 & 6 & 2 & 1 & \\
\hline Ssa16 & 1 & 5 & 32 & \\
\hline Ssa17 & & & & 1 \\
\hline \multicolumn{5}{|l|}{ Ssa18 } \\
\hline Ssa19 & & 2 & 15 & \\
\hline Ssa20 & & & & 18 \\
\hline \multicolumn{5}{|l|}{ Ssa21 } \\
\hline Ssa22 & 2 & & 49 & \\
\hline \multicolumn{5}{|l|}{ Ssa23 } \\
\hline Ssa24 & & & & 15 \\
\hline \multicolumn{5}{|l|}{ Ssa25 } \\
\hline Ssa26 & & & & 54 \\
\hline Ssa27 & & 2 & & \\
\hline \multicolumn{5}{|l|}{ Ssa28 } \\
\hline Ssa29 & & & & \\
\hline Total & 120 & 58 & 121 & 134 \\
\hline
\end{tabular}

612

613

614

615

616

617

618

619

620

621 
Table 3. SNPs and regions under selection identified by $X P E H H$ among population pairs and chromosomes.

\begin{tabular}{|c|c|c|c|c|c|c|}
\hline & \multicolumn{2}{|c|}{ Pop-A/Pop-B } & \multicolumn{2}{|c|}{ Pop-A/Pop-C } & \multicolumn{2}{|c|}{ Pop-A/Pop-D } \\
\hline & SNPs & Regions & SNPs & Regions & SNPs & Regions \\
\hline \multicolumn{7}{|l|}{ Ssa01 } \\
\hline Ssa02 & 68 & 3 & 82 & 5 & 17 & 2 \\
\hline \multicolumn{7}{|l|}{ Ssa03 } \\
\hline \multicolumn{7}{|l|}{ Ssa04 } \\
\hline Ssa05 & 11 & 1 & & & 26 & 3 \\
\hline \multicolumn{7}{|l|}{ Ssa06 } \\
\hline \multicolumn{7}{|l|}{ Ssa07 } \\
\hline \multicolumn{7}{|l|}{ Ssa08 } \\
\hline Ssa09 & 289 & 17 & 71 & 3 & 6 & 1 \\
\hline Ssa10 & 16 & 2 & 571 & 13 & 154 & 4 \\
\hline Ssa11 & & & & & 10 & 2 \\
\hline \multicolumn{7}{|l|}{ Ssa12 } \\
\hline \multicolumn{7}{|l|}{ Ssa13 } \\
\hline Ssa14 & & & 1 & & 8 & 1 \\
\hline Ssa15 & & & 7 & 1 & & \\
\hline Ssa16 & & & 25 & 1 & & \\
\hline \multicolumn{7}{|l|}{ Ssa17 } \\
\hline \multicolumn{7}{|l|}{ Ssa18 } \\
\hline \multicolumn{7}{|l|}{ Ssa19 } \\
\hline \multicolumn{7}{|l|}{ Ssa20 } \\
\hline \multicolumn{7}{|l|}{ Ssa21 } \\
\hline \multicolumn{7}{|l|}{ Ssa22 } \\
\hline \multicolumn{7}{|l|}{ Ssa23 } \\
\hline Ssa24 & 53 & 4 & & & 8 & 1 \\
\hline \multicolumn{7}{|l|}{ Ssa25 } \\
\hline Ssa26 & & & & & 32 & 1 \\
\hline \multicolumn{7}{|l|}{ Ssa27 } \\
\hline \multicolumn{7}{|l|}{ Ssa28 } \\
\hline Ssa29 & & & 7 & 2 & 1 & \\
\hline Total & 437 & 27 & 764 & 25 & 262 & 15 \\
\hline
\end{tabular}




\section{$632 \quad$ Figure legends}

633

634

635

636

637

638

639

640

641

642

643

644

645

646

647

648

649

650

651

652

653

654

655

656

657

658

659

660

661

662

663

664

665

666

667

668

669

670

671

672

673

674

675

676

677

678
Figure 1. Individual assignment probabilities generated with ADMIXTURE $(1 \bullet \mathrm{K} \bullet 12)$. Each color represents a cluster, and the ratio of vertical lines is proportional to assignment probability of and individual to each cluster.

Figure 2. Genome-wide distribution of $-\log 10$ (p-value) of standardized Integrated Haplotype Score $|\mathrm{iHS}|$ among Atlantic salmon populations.

Figure 3. Genome-wide distribution of $-\log 10$ ( $\mathrm{p}$-value) of standardized cross-population extended haplotype homozygosity (XP-EHH) scores in pairwise Atlantic salmon populations.

Figure 4. GO enrichment analysis of genes with evidence of selection in Atlantic salmon. GO functional classification was performed using the DAVID browser. 
bioRxiv preprint doi: https://doi.org/10.1101/525550; this version posted January 20, 2019. The copyright holder for this preprint (which was not certified by peer review) is the author/funder. All rights reserved. No reuse allowed without permission.

\section{Figure 1}

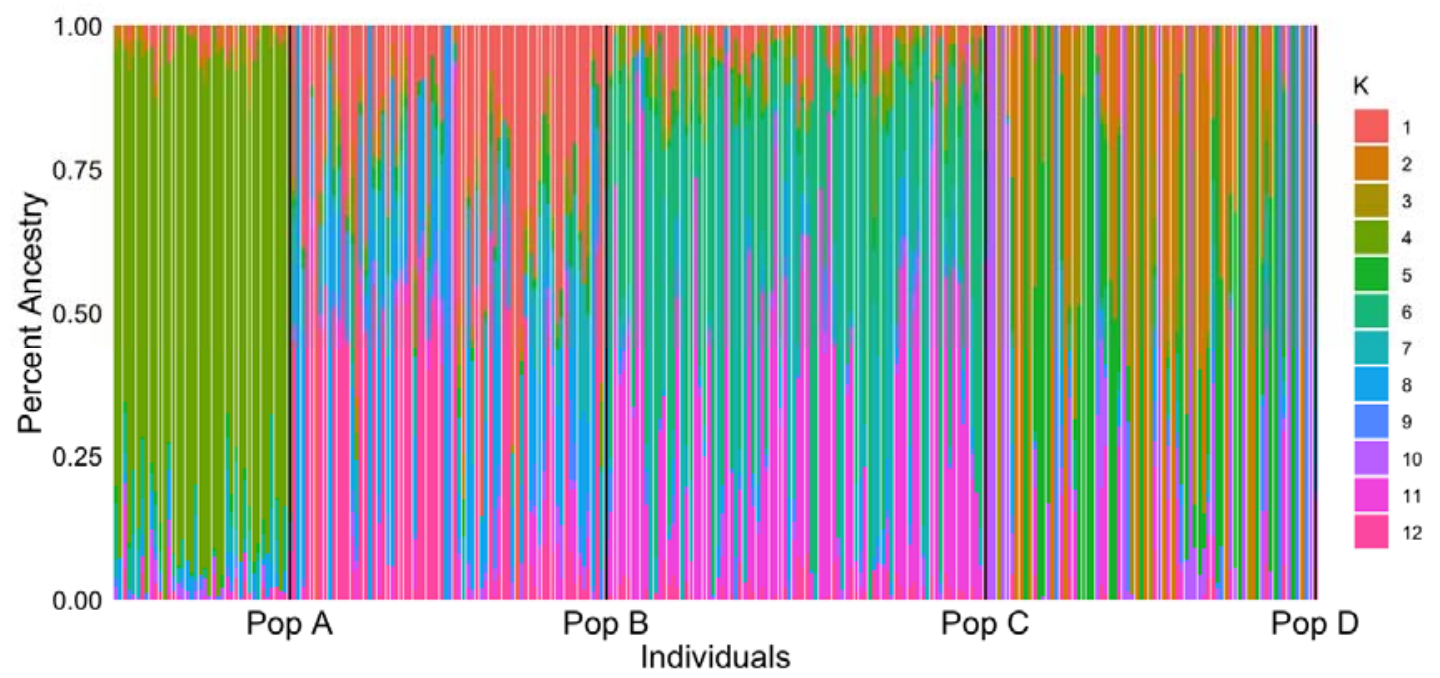


bioRxiv preprint doi: https://doi.org/10.1101/525550; this version posted January 20, 2019. The copyright holder for this preprint (which was not certified by peer review) is the author/funder. All rights reserved. No reuse allowed without permission.

A. |iHS| PopA

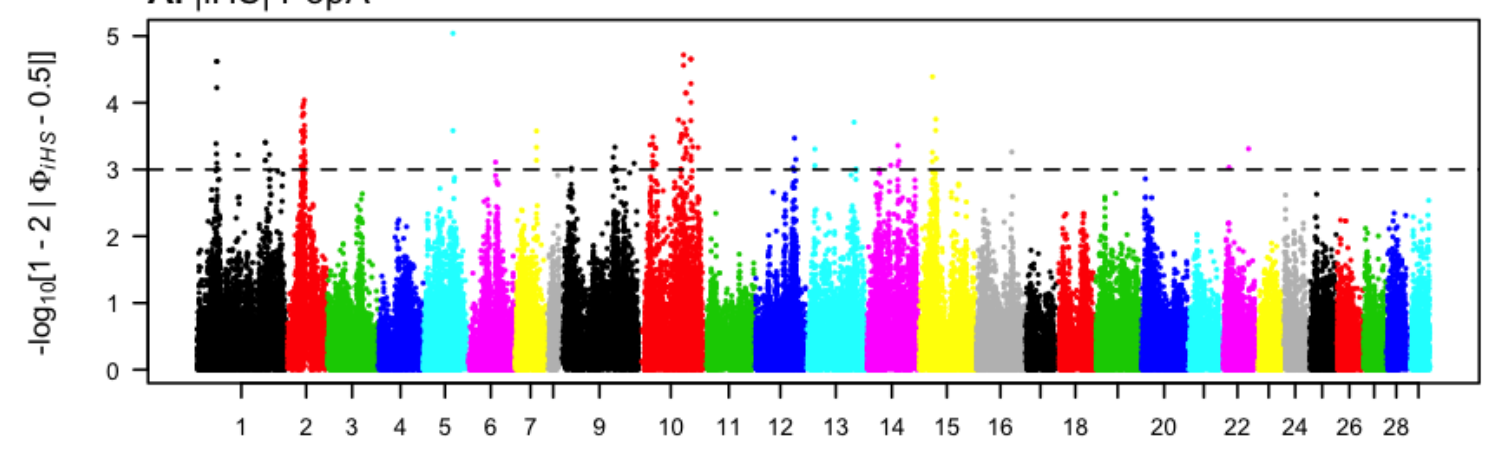

B. |iHS| PopB

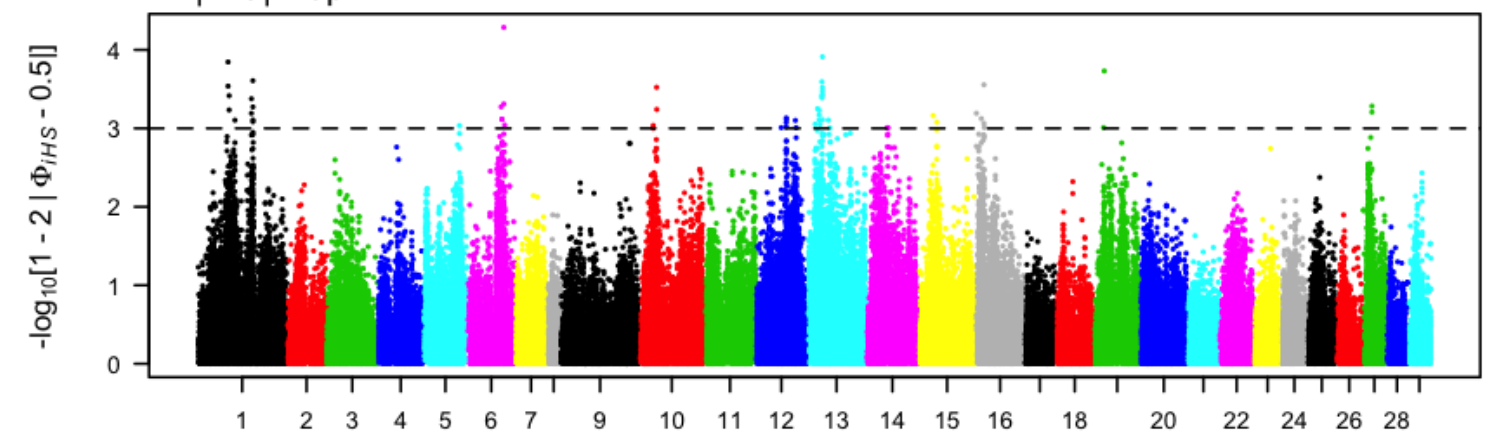

C. |iHS| PopC

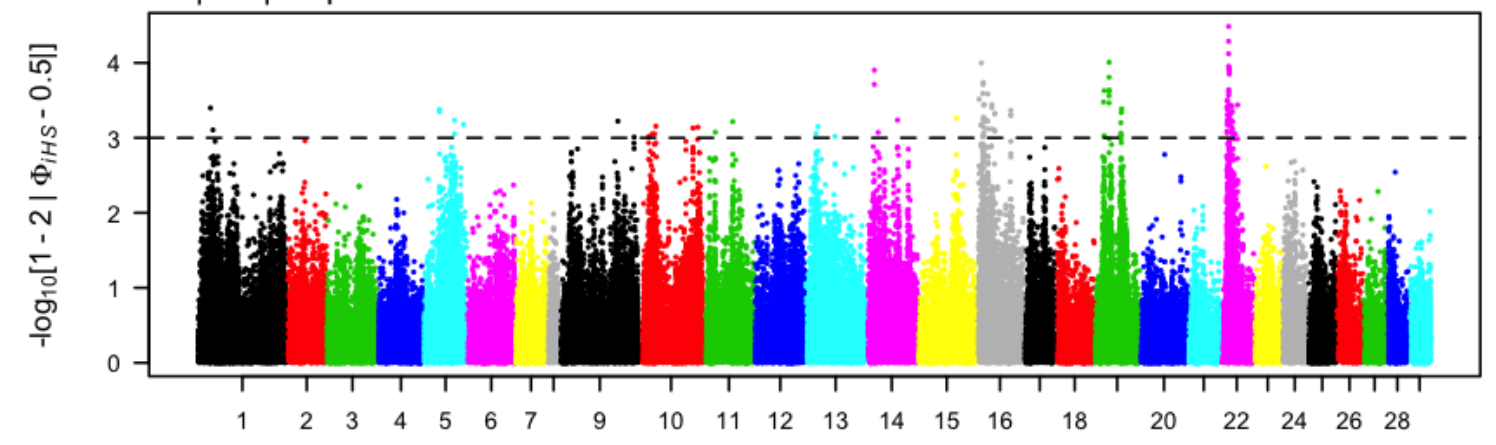

D. |iHS| PopD

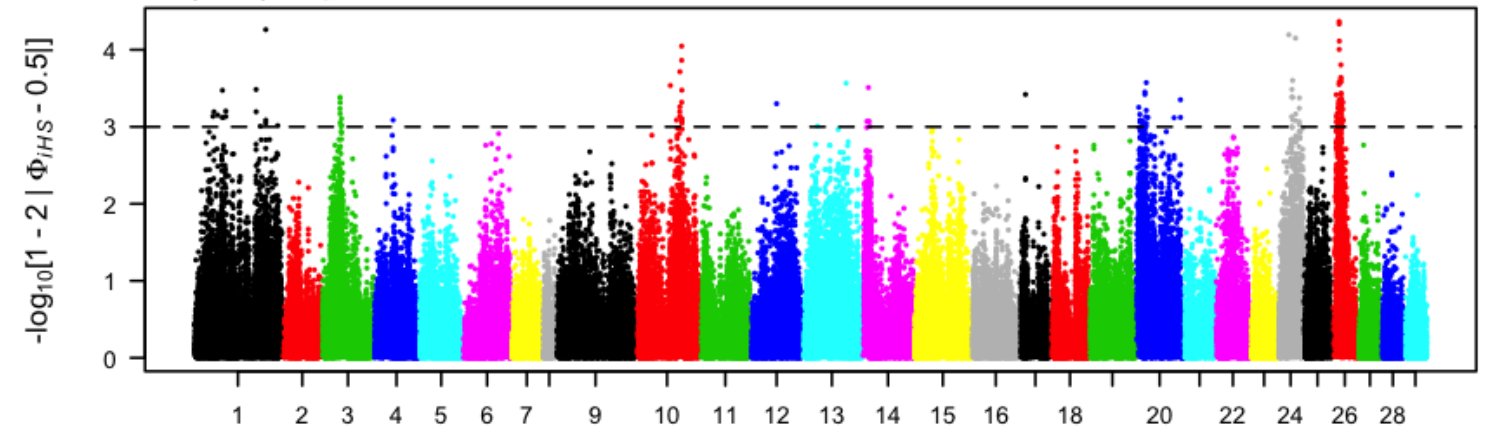


bioRxiv preprint doi: https://doi.org/10.1101/525550; this version posted January 20, 2019. The copyright holder for this preprint (which was not certified by peer review) is the author/funder. All rights reserved. No reuse allowed without permission.

713

714

715

\section{Figure 3}

A. XPEHH PopA/PopB

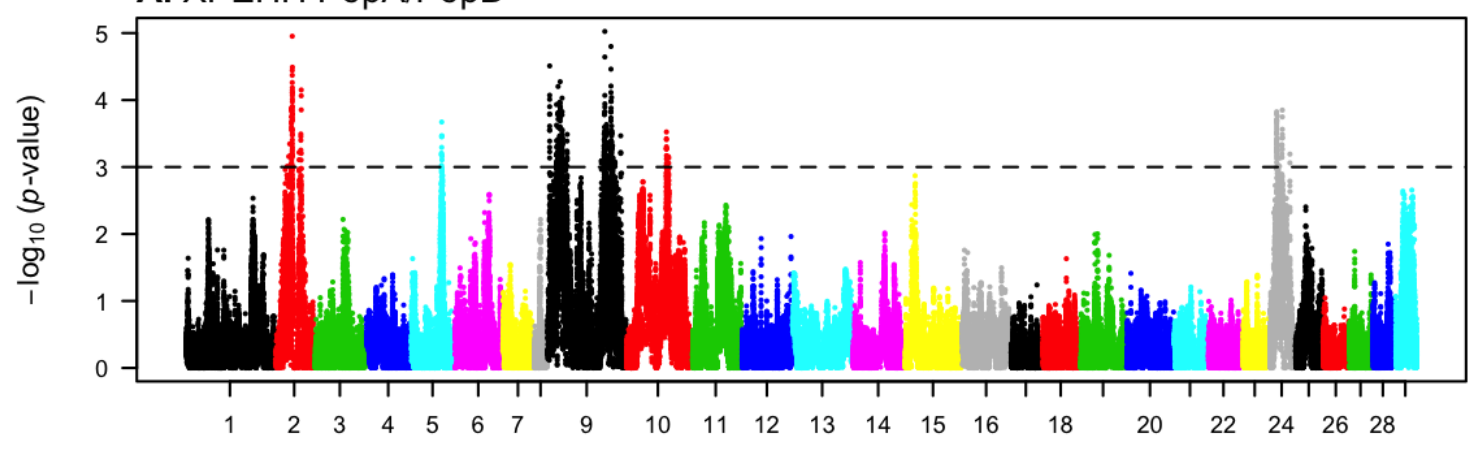

B. XPEHH PopA/PopC

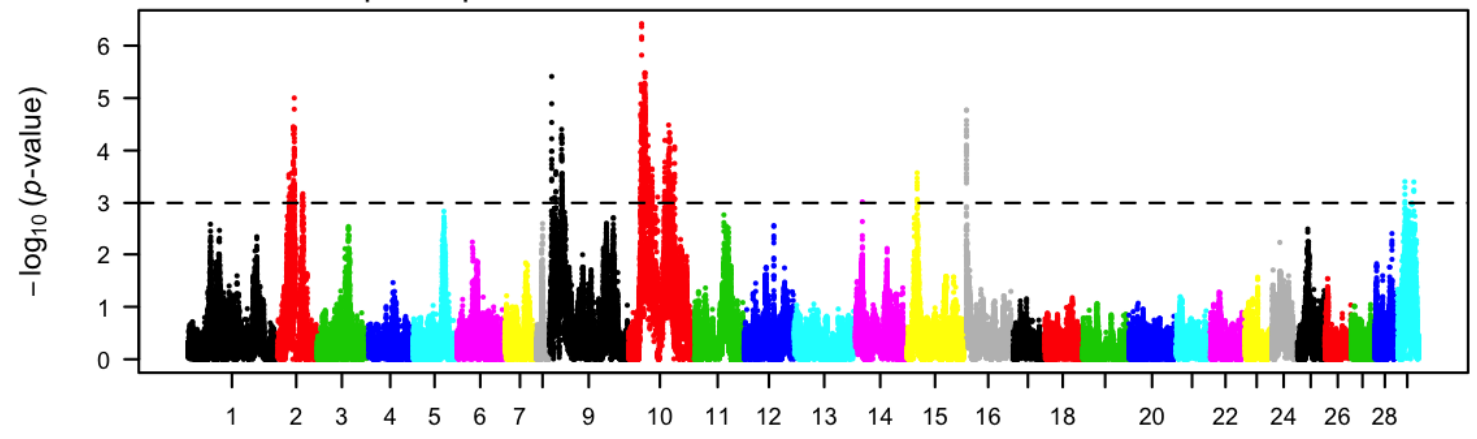

C. XPEHH PopA/PopD

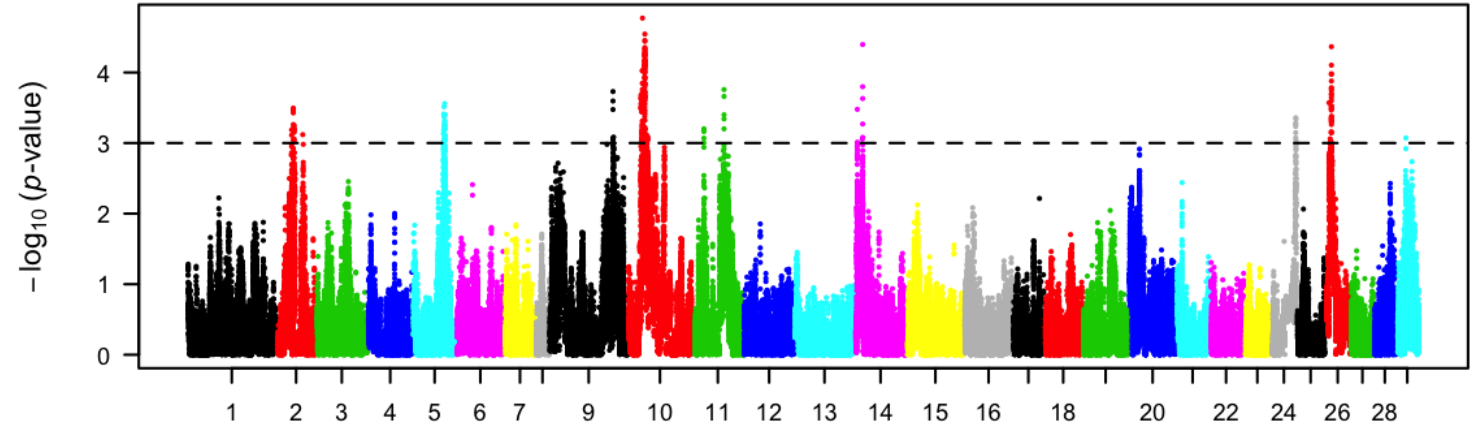

716

717

718

719

720

721

722

723

724

725

726

727 
bioRxiv preprint doi: https://doi.org/10.1101/525550; this version posted January 20, 2019. The copyright holder for this preprint (which was not certified by peer review) is the author/funder. All rights reserved. No reuse allowed without permission.

\section{Figure 4}
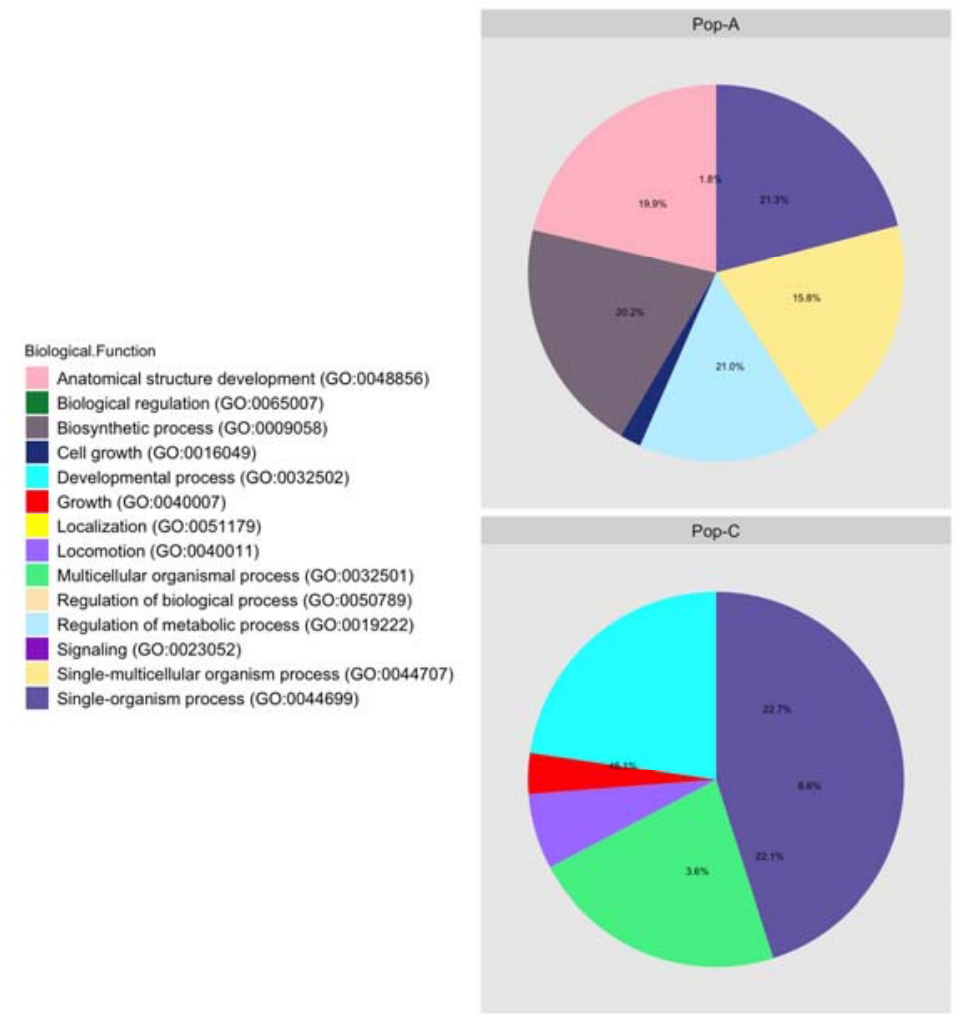



